\title{
Information Flow Analysis and the Theory of the Firm
}

\author{
Paul Clyde* \\ Ross School of Business, University of Michigan, Ann Arbor, MI, USA
}

\begin{abstract}
In this paper, I examine the role the firm plays in economizing on information flows that are required to turn raw materials and ideas into products and services used by final consumers. Specifically, I argue that scale economies associated with complex information transfers are an important benefit of integration. This argument is distinct from theories that are based on incentives and leads to different or more refined conclusions in some cases. The differences are explored in the context of literature on specific assets, vertically related monopolies, and physical asset ownership. Information flow analysis also arms managers with a framework for addressing organizational questions beyond firm-boundary decisions such as intrafirm decisions. Copyright $\left({ }^{0} 2014\right.$ John Wiley \& Sons, Ltd.
\end{abstract}

\section{INTRODUCTION}

Coase (1937) motivates his essay on the firm by pointing out that 'Economists in building up a theory have often omitted to examine the foundations on which it was erected. This examination is, however, essential not only to prevent the misunderstanding and needless controversy which arise from a lack of knowledge of the assumptions on which a theory is based, but also because of the extreme importance for economics of good judgment in choosing between rival sets of assumptions' (p. 386). His subsequent discussion of the role of coordination through the market versus coordination within a firm aimed at remedying one such omission: an examination of the role and boundaries of the firm. Beginning with Alchian and Demsetz (1972), there has been an increasing focus on what constitutes a firm. However, there is no consensus. Many follow the lead of Jensen and Meckling (1976) in viewing the firm as a nexus of contracts. An

\footnotetext{
*Correspondence to: Ross School of Business, University of Michigan. E-mail: pclyde@umich.edu
}

alternative definition can be found in the work of Grossman and Hart (1986) who 'define the firm as being composed of the assets (for example, machines, inventories) that it owns' (p. 692). Because many contracts can be and are between individuals, not just physical capital, the former definition addresses human capital, whereas the latter is limited to physical capital. Much of the subsequent literature on firm boundaries can be divided into these two related questions: (1) what determines the ownership of physical assets and (2) what determines the organization of human capital? However, many papers that address these questions omit a significant examination of a foundation on which they are erected: information flows. My goal in this paper is to examine the nature of information and apply an analysis of its transfer to business decisions beginning with decisions related to the organization of human capital. In doing so, I will show that a number of leading theories on firm boundaries ultimately rely on information flow analysis. In the process, I will show how an information flow approach refines the arguments in ways that can shed light on some debates in the academic literature and, 
perhaps more importantly, provide more guidance to managers.

The organization of human capital is related to and arguably precedes the question of physical capital: much of the literature on ownership of physical assets is based on incentives and thus presupposes an organization of human capital (people have incentives, physical assets do not). The importance of being clear about the distinction between the two approaches to theory of the firm-human capital versus physical capital — can be seen in the debate between Coase and Klein over the GM-Fisher Body merger. Much of Klein's (2007) detailed analysis of the GM-Fisher Body merger at the beginning of the 20th century focuses on physical assets. In the article that precipitated the debate, Klein et al. (1978) cited tools and dies as a source of gains from integration, but after more information became available, Klein (2007) determined that 'Rather than tools and dies, the long-term exclusive dealing contract can be explained as protecting the very large expansion in capacity Fisher Body undertook in 1919 to handle the expected General Motors business... Fisher Body's investments in plant and equipment were not completely GM specific. However, there was a significant GM-specific element in these productive assets...' (p. 5). Thus, although elsewhere Klein identifies human capital as an important factor (e.g., Klein, 1988), he is also interested in and, in his 2007 article, emphasizes physical capital. In contrast, Coase (2006) appears to exclude purchases of physical assets from his definition of vertical integration. In his consideration and then rejection of what later became known as the asset specificity argument: 'I ultimately came to reject the existence of this risk as an important reason for vertical integration as a result of discussions I had with businessmen. They were unimpressed by my argument. They pointed out that if equipment was required solely for one particular customer, the cost would normally be reimbursed by that customer ... opportunism in connection with asset specificity did not normally pose any problem and certainly not one that would call for vertical integration' (p. 259). Assuming reimbursement of equipment costs is accompanied by transfer of ownership of the equipment to the customer, ${ }^{1}$ Coase does not consider the purchase of the equipment to be vertical integration. Instead, Coase is interested in the organization of human capital. Citing an article by Casadesus-Masanell and Spulber (2000), Coase says 'They state that the merger (between GM and Fisher) was "directed at improving coordination of production and inventories, assuring GM of adequate supplies of auto bodies, and providing GM with access to the executive talents of the Fisher brothers" (id). "The executive talents of the Fisher brothers" were particularly important in implementing Sloan's organization reforms in the 1920s. "Sloan required managers capable of coordinating complex operations, making decisions in a decentralized organization, and using common resources effectively" (id, p. 100)' (p. 268). Coase is interested in the role of integration in organizing human capital.

Demsetz (1988) is also interested in the organization of human capital and was among the first to highlight the role of information and knowledge in determining firm boundaries. ${ }^{2}$ In particular, he argues that 'firm-like' activities facilitate a specialization in knowledge. Knowledge can be transferred through education or through lower-cost mechanisms such as direction and transfer of rights to ownership (selling a finished product is one way to transfer the information that goes into making the product). Demsetz concludes that 'the vertical boundaries of the firm are determined by the economics of conservation of expenditures on knowledge' (p. 159).

One particular aspect of information flows, which I refer to as complexity in this paper, plays a central role in the analysis in the present paper and has received increased attention more recently. Gant et al. (2002), for example, point out that 'unlike other forms of capital, social capital cannot be traded by individuals on an open market, but is instead embedded within a group ... (T)he social structure of relationships among employees provides the infrastructure through which information and knowledge flow. ... these networks for transmitting information cannot simply be replaced by operating manuals and standard operating procedures' (p. 297). Coase's (2006) emphasis on the managerial capabilities of the Fisher brothers suggests something similar. Empirical work shows that firms are the preferred venue for complex information flows, whereas relatively simple, codifiable information can flow between firms. Azoulay (2004) examines the choice of outsourcing Food and Drug Administration (FDA) tests within the pharmaceutical industry and finds that when the pharmaceutical company is learning from the testing process (e.g., because the drug is part of a newer class of drugs), it is more likely to vertically integrate and conduct the testing itself. However, when the drug is more similar to existing drugs, the pharmaceutical company is more likely to outsource the testing to a CRO. He explains this by arguing that the pharmaceutical company is less likely to learn anything from the testing in this case and just wants the tests completed to satisfy the FDA. Kogut 
and Zander (2003) survey a group of Swedish firms responsible for 35 major innovations to determine when the firm would commercialize the innovation through a wholly owned subsidiary versus transfer the innovation rights to a separate firm. They find that firms are more likely to keep the innovation in-house when the knowledge is less codifiable, has numerous critical and interacting variables, and requires knowledge that is costly to teach to another person. Monteverde (1995) shows that greater levels of unstructured technical dialog between fabrication and development engineering in the semiconductor industry lead to greater levels of vertical integration.

In this paper, I use the analysis of Demsetz (1988), Azoulay (2004), and Kogut and Zander (2003), which I describe as information flow analysis, and show that it is at the heart of other lines of literature. Section 2 describes information flow analysis as I use it in this paper beginning with a discussion of the different types of information and continuing with an examination of the information-related costs and benefits of using firms as a mechanism for transferring complex information. ${ }^{3}$ Section 3 applies information flow analysis to the asset specificity literature arguing that specificity is often due to and varies with the complexity of information flows. It also shows where there are differences between the two arguments. Section 4 ties information flow analysis to the ownership of physical capital. Because much of the literature on physical assets is based on incentives, it is critical to understand the incentives of the agents acting on behalf of the rest of the firm's stakeholders. Thus, analysis of physical asset ownership depends on an understanding of the organization of human capital. Two sets of studies are reviewed in this section to illustrate the point. Section 5 shows that some of the traditional arguments for vertical integration including scale economies and sequential monopolies are incomplete without any analysis of the information flows.

\section{INFORMATION FLOWS AND FIRM BOUNDARIES}

Turning raw materials and ideas into products and services that can be used by final consumers requires transferring not only physical goods but also vast amounts of information between all of the different individuals involved in the process. Information flow analysis argues that one important function of a firm is to economize on this costly activity. This suggests that bits of information should be the base unit of analysis

Copyright (C) 2014 John Wiley \& Sons, Ltd. in understanding the organizational relationships. In a sense, this is parsing transactions, Williamson's (1985) base unit of analysis (and Coase, 1988, p. 4), into finer components. Williamson's transaction costs include $e x$ ante costs such as 'drafting, negotiating and safeguarding an agreement' (p. 20) and ex post costs such as maladaptation costs, haggling costs, costs of governing the transactions, and credible commitment costs. ${ }^{4}$ Information flow analysis focuses instead on the complexity of the information being transferred across the different parties in the transaction. This approach allows different components of the transaction costs to be borne by different entities. For instance, individuals within firm A may transact with individuals within firm B by having firm B employees provide software planning and development services to firm A. Within that transaction, however, there are many different interactions between different individuals in the two firms. What role do the employees of the customer (firm A) play in the planning and development of the code? What role do the employees of the software firm (firm B) play? In some instances, the software developer (employees of firm B) may be given a basic overall goal and then sent off to develop the software. In other instances, the software developer employees may work on very small iterations, constantly returning to the employees of the customer for progress reports and guidance on next steps. Both are transactions, but the information flows differ significantly between the two. Understanding the circumstances under which one is preferable to the other requires an understanding of the types and timing of information being transferred. Using information as the base unit of analysis also differs from the transaction cost approach in that, like traditional scale economy arguments, it emphasizes productive efficiency instead of incentives in determining firm boundaries, although both play a role. Both incentives and productivity also play a role in transaction cost analysis, but the emphasis there is on incentives. ${ }^{5}$

\subsection{Complex Information}

But what is 'complex information'? A taxonomy developed in the 1950s and still widely used today, Bloom's taxonomy, illustrates variation in complexity as the term is used in this paper. Bloom's taxonomy is the result of work by Benjamin Bloom (1956) and his colleagues to develop a hierarchy of educational goals. ${ }^{6}$ They define the base level, which they call 'knowledge', as the memorization of facts. ${ }^{7}$ Higher-order thinking is required as one moves up the taxonomy to comprehension of the 
facts, the ability to apply the facts, analysis of the facts, synthesis of different concepts and facts, and finally evaluation or the ability to make judgments. Information at the highest level of complexity is costly to transfer. Teaching judgment can take years of repeated interactions and experiential learning; it is not easily codifiable. Transferring basic information, knowledge in Bloom's parlance, entails few costs: numbers on a piece of paper will suffice. No personal interaction is necessary.

Although the language differs, this notion of complexity is consistent with that used in other articles on information flows. As mentioned, Demsetz uses the term knowledge instead of information, and Gant et al. include something that amounts to complex information flows as part of their description of social capital. Azoulay (2004) distinguishes between 'data production-the routine manipulation, storage and transfer of symbolic information within established categories; and knowledge production-the establishment of novel conceptual categories, hypotheses and causal associations' ( $p$ 1591). Kogut and Zander (2003) use teachability (the cost of teaching knowhow), codifiability (the degree to which information can be written down in documents), and complexity (number of interacting elements in a given activity) in their study of production of innovations. ${ }^{8}$ Indeed, the degree to which information is codifiable is a useful way to think of the degree of complexity.

Complexity as it is used in this paper is, however, different from other delineations of information types such as Jensen and Meckling's (1992) discussion of general and specific information. Jensen and Meckling define specific knowledge 'as knowledge that is costly to transfer among agents'. To illustrate this point, they use Hayek's (1945) example of how to determine empty space on a freighter. In this case, specific information about the location and timing of the space is required; general knowledge such as '(a)ggregating or lumping together items such as location or quality destroys (the data's) usefulness' (p. 4). Other examples of specific knowledge cited by Jensen and Meckling include 'knowledge of specific skills or preferences of individuals, or the peculiarities of specific machines, knowledge of particular unemployed resources or inventories, and knowledge of arbitrage opportunities' (p. 6). Like complex information, specific knowledge is costly to transfer; however, in the examples described earlier, transfers are costly because vast quantities of simple information are being transferred, not because complex information is transferred. This difference between complex information and specific information is

Copyright () 2014 John Wiley \& Sons, Ltd. important. Complex information can be received by a given individual and usefully aggregated. That is, although specific pieces of information may not be recalled, the individual can recall the combination of lessons learned from complex information flows in a way that is useful to the individual. By contrast, and as Jensen and Meckling point out, the large volume of simple information described by Jensen and Meckling as specific (e.g., data on capacity utilization) cannot be aggregated in a way that is useful to a single individual.

\subsection{Costs and Benefits of Internalizing Information Flows}

This section describes some of the main costs and benefits of organizing within a firm as they relate to information flows. Other costs and benefits, including many related to incentives, are not discussed here. This does not mean that these other costs and benefits are unimportant. The point of this discussion is to highlight some information-related costs and benefits that should be included (along with the other costs and benefits) in decisions about firm boundaries.

\subsubsection{Benefits}

The central argument of information flow analysis is that one of the principal benefits of operating within a firm is the efficiency with which the individuals in the firm transfer complex information. This argument rests on three conditions: (1) employment increases the likelihood that a given individual is going to be involved in repeated transfers of complex information; (2) information-sharing costs will be higher when the information being transferred is more complex; and (3) there are scale economies to transfer complex information. Consider the plausibility of each.

Employment could increase the likelihood that a given individual is involved in repeated interactions either because employment gives the owners more control over who is involved in information transfers or because employment represents a credible commitment to employees. Owners will have more control over which individuals are involved in information transfers when the individual is an employee than when the individual works for an independent contractor. Azoulay (2004) found that independent contract research organizations (CROs) would sometimes substitute which individuals were interacting with the pharmaceutical company to the detriment of the pharmaceutical company. Employees at pharmaceutical companies therefore preferred integration into FDA testing when they valued controlling the choice of individuals involved in the FDA testing. Employment 
could also represent a credible commitment to a longterm relationship between the owner(s) and individuals employed at the firm. Firm owners could try to commit to independent contractors in a similar way. However, there seems to be some sense among employees and employers alike that there is a greater commitment through employment. Part of that may be legal (Masten, 1988), but part goes beyond the law. ${ }^{9}$

The second condition - the cost of transferring information increases as the complexity increasesholds because complex information is not easily transferred through simple written documents or emails. Complex information transfers typically require iterative personal interactions. For instance, teaching an employee how to interact with different customers can require experience interacting with the customers in the presence of both the teacher and the student. It may not be possible to anticipate all circumstances that will arise, and thus, the teacher must convey a sense of judgment to the student. The information being transferred in this case is highly complex: the ability to judge how to interact in multiple situations, some of which cannot be anticipated. Because teaching judgment requires so much interpersonal interaction, it is very costly.

The third condition-scale economies in transferring complex information-means that repeated interactions economize on the amount of information that needs to be exchanged. As the number of complex information exchanges increases between two individuals, both individuals develop a stock of information that can be used in all future exchanges. ${ }^{10}$ For instance, teaching judgment the first time is very costly. However, once taught, that ability to make judgments exists and can be drawn on for future interactions. ${ }^{11}$ This is why teams in sports or in business that are composed of individuals who have worked with each other over a long period can be much more efficient than teams recently combined even if the latter is composed of all stars and the former is not.

The claim of this paper is that the magnitude of the benefit of conducting economic activity within a firm's boundaries is an increasing function of the interaction of complexity of information transfers and the number of times these transfers take place. The latter can be further divided into frequency and duration of the transfers. To see the importance of the interaction between frequency, duration, and complexity, consider some examples that include two of the components, but not all three. The relationship between general construction contractors and a subcontractor

Copyright () 2014 John Wiley \& Sons, Ltd. requires frequent transfers of information and sometimes for long periods (the two may work together on multiple projects over a number of years). However, the information is simple-telling an electrician what day to show up and providing blueprints-and therefore relatively costs little to transfer. Consequently, subcontractors are not employees of the general contractor. Consulting firms exchange complex information with clients and may do so frequently, but only for the duration of the consulting project. The consulting firm generally remains separate from the client. ${ }^{12}$ Accountants may work with a firm for years exchanging somewhat complex information for tax and other accounting purposes but do so infrequently. They often operate as an external advisor to the firm.

In addition to the central benefit of information flow analysis described earlier-economizing on complex information transfers - there is a second information-related benefit to integrating. Integration can resolve common agency problems: agents within a firm may have more incentive to share the information than agents between firms do. ${ }^{13}$ For example, in the pharmaceutical industry, there are a limited number of vendors (external suppliers) that store and ship chemicals, vaccines, and biologics to the research departments at major pharmaceutical companies. The costs of shipping and storing these supplies have led staff at some firms to engage in major cost reduction initiatives, initiatives that often involve employees of both the vendor and the pharmaceutical company. However, employees within each vendor may be reluctant to share the information with employees within the pharmaceutical companies for two reasons. First, any cost reductions that an employee of a vendor (V1) discovers and shares with employees of the pharmaceutical company may be shared with employees of the pharmaceutical company's other vendors (V1's competitors) in an effort to reduce supply chain costs across all vendors. Second, an employee of a vendor (V1) who knows how to reduce costs because of work with a pharmaceutical company (P1) may be reluctant to reveal it to employees of another pharmaceutical company (P2) out of fear that P2 will view that as an indication that V1 is not trustworthy. That is, P2 may view the sharing of P1's cost reductions as a breach of trust (company secrets) between V1 and P1 and therefore be concerned that some of their own (P2's) secrets are being shared with their competitors. P2 may therefore be less willing to work with V1.

\subsubsection{Costs of Internalizing Information Flows}

The first, and arguably most important, cost of integration is the principal-agent problem. This is discussed 
in considerable detail elsewhere and will not be discussed further here, ${ }^{14}$ but one form this may take is particularly important in the present context (and will be used in further discussion later): a reduction in effort to engage in a costly exchange of complex information with parties outside of the newly integrated firm. Consider a vertically related set of independent firms: supplier $\mathrm{Z}$, manufacturer $\mathrm{Y}$, and retailer $\mathrm{X}$. If supplier $\mathrm{Z}$ merges with manufacturer $\mathrm{Y}$, this may improve the efficiency of information sharing between employees of $\mathrm{Z}$ and $\mathrm{Y}$ (as described earlier), but it may reduce the efficiency of information sharing between the employees of the newly merged firm, ZY, and employees of retailer $\mathrm{X}$ relative to the interaction between employees of $\mathrm{X}$ and employees of $\mathrm{Y}$ that took place before the merger. To the extent that employees at $\mathrm{ZY}$ are now more insulated from the discipline of the market, they will have less incentive to invest in costly exchange of complex information. The same holds true if $\mathrm{Z}$ and $\mathrm{Y}$ are horizontally related as long as the merger increases the principal-agent problem by decreasing the effect of market discipline on employee's behavior.

Second, employees within a firm may have less access to market information after integration. This is distinct from the cost described earlier in that the principal-agent problem describes lack of effort by employees within the firm to gather information. This second cost relates to information available to them. Even if employees exert the same amount of effort after the merger to gather information, they may have access to less either because employees higher up the hierarchy fail to share the relevant information or because there are more costs associated with gaining access to the relevant information.

Third, in order to gain the benefits of economizing on complex information flows, significant upfront costs are incurred in the form of information accumulation. It takes time and effort to gain the stock of information that allows a firm to operate efficiently.

Finally, firm leadership can become overwhelmed with the amount of information needed to operate efficiently, a component of the textbook example of increased management costs (e.g., Pindyck and Rubinfeld, 2013, p. 255). The larger the firm, the greater the amount of information flowing to the firm and the more likely the leadership will have to rely on employees other than themselves to generate information (Bolton and Dewatripont, 1994). This introduces a need for mechanisms to share the information between the different employees, thereby increasing the cost.

Copyright $@ 2014$ John Wiley \& Sons, Ltd.

\subsection{Information Flows and Interactions with Individual Customers}

A focus on firm boundaries can conceal information transfers between a firm and its individual customers. Yet, if one of the central roles of organizational forms is to economize on the information flows needed to transform natural resources and ideas into products and services usable to customers, the interaction between the final customer and the retailing firm is important. Information flow analysis may reveal benefits to frequent, complex information transfers between the final consumer and the retailer, but integration is typically not an option with an individual consumer. ${ }^{15}$ How is this best handled by the organization? Although the integration of retailer $\mathrm{X}$ with the consumer is not possible, manufacturer $\mathrm{Y}$ does have a choice about integrating with retailer X. Following the logic described earlier on the incentive cost of internalizing economic activity, an increase in the benefits of close interactions between the employees of the retailer and the individual customer increases the costs of reduced effort that results when manufacturer $Y$ integrates with retailer $\mathrm{X} .{ }^{16}$ Thus, information flow analysis suggests that integration of $\mathrm{X}$ and $\mathrm{Y}$ will be less beneficial as the amount and complexity of information transfers between the final consumer and the retailer increases.

\section{INFORMATION FLOWS AND SPECIFIC INVESTMENTS}

Information flow analysis is distinct from some of the more widely accepted theories of the firm. Often, the distinction is in the emphasis on the cost of transferring information instead of incentives. The remaining sections explore other theories and show that, in some cases, these theories by themselves do not explain when it is beneficial to integrate. ${ }^{17}$ An understanding of the complexity and timing of information flows is also required. In other instances, the conclusions that result from information flow analysis can differ from those of other theories. Because of its prominence in theory of the firm literature, I begin with and examine in some detail the literature on asset specificity.

\subsection{Opportunism and Specific Investments}

Klein et al. (1978) and Williamson $(1979,1985)$ argued that intrafirm transactions reduce opportunism on specific investments. This theory has played a prominent role in the literature on firm boundaries 
and enjoys considerable empirical support. ${ }^{18}$ Klein, Crawford, and Alchian use the example of a printing press that is leased to publisher B by printer A. The cost of providing the service is $\$ 4000$ in fixed costs and $\$ 1500$ in variable costs. If publisher B does not use it, publisher $\mathrm{C}$ is willing to pay the next highest amount at $\$ 3500$ (which, by assumption, exceeds the salvage value). Publisher B might have been willing, ex ante, to pay the $\$ 5500$ needed to allow printer A to break even. However, once the investment is made, publisher $\mathrm{B}$ could decrease the price it pays to printer A to as low as $\$ 3500$, and printer A's most profitable response will be to accept that despite the fact that it does not cover the costs incurred. Realizing this possibility upfront, printer A would ask for some sort of assurance that this will not happen. That assurance can be contractual (e.g., a forfeitable bond of $\$ 2000$, which goes to printer $\mathrm{A}$ in the event that publisher B changes the terms), or it can take the form of vertical integration (i.e., A buying $\mathrm{B}$ or vice versa).

The benefit of integration, under the asset specificity argument, is that it eliminates the concern printer A has about receiving its return once the investment is made. There are two reasons for printer $\mathrm{A}$ to be concerned. The first, and the focus of most of the literature on opportunism, is duplicity on the part of publisher B: once printer $\mathrm{A}$ has made the investment, publisher B could take advantage of printer A by offering to pay a much lower price than was initially agreed upon. The second reason is differing expectations of the future. Publisher B wants to use printer A because publisher B believes the demand for its product will be sufficient to cover the costs of printer $\mathrm{A}$ and all other costs publisher B incurs. Printer A might not agree with publisher B's assessment about the future demand for publisher B's product. Yet, to the extent that printer A's compensation is based on the amount of printing (in the extreme, publisher B may go bankrupt because of lack of demand, leaving printer A with zero compensation), printer A would incur some of the cost of an incorrect assessment of future demand. Whether the concerns are related to duplicity or differing expectations, integration of publisher B with printer A solves the problem.

\subsection{Opportunism and Complex Information}

There are at least two alternative solutions, however. First, publisher B could buy the printing equipment rather than leasing it from an independent firm. This will solve both the duplicity and the differing expectations problem. However, this will only be a cost-effective

Copyright () 2014 John Wiley \& Sons, Ltd. alternative if publisher B is as efficient at deploying the printing assets as printer $\mathrm{A}$ is, a condition that is less likely the more complex the information needed to efficiently use the printing assets. For example, printer A may more efficiently process the information necessary to monitor and maintain the equipment. Printer A may have in-depth knowledge about how the printer works, when a different printer would be optimal for the needs of that particular customer, and so on. If publisher B buys the printing equipment, publisher B would be required to learn all of this. This learning may be a complex information flow making the form of integration considered here (publisher B buying its own printer) a costly solution when compared with buying printing services on the market.

A second possibility is for publisher B to sell to printer A the information about publishing that makes the investment profitable. The information would be about both how to produce the final product and why the investment is profitable. Selling the information would address the duplicity problem because the investment could no longer be expropriated by the employees of publisher $\mathrm{B}$; the rights to the information have been transferred. If all of the other elements of production are readily available in the market, publisher B need not even be involved anymore, much less have any ability to 'hold up' printer A. Differing expectations can also be addressed by information transfers. The reason the leadership of publisher B wants the investment made is because it believes it can earn a return on the investment in the printing equipment. This is based on information it has about the costs of production and about publisher B's market demand. Publisher B just needs printer A to supply some component (the printer). However, if the leadership of printer A has the same information that the leadership of publisher B has, printer A's leadership would understand the value of the investment and be just as willing to make the investment. The problem is that transferring this information can be extremely costly.

Note that the differences in these solutions are not in the physical assets. The physical assets are owned and used by a single party whether it is through integration of publisher B and printer A, publisher B selling the information about the idea to printer $\mathrm{A}$, or publisher B just buying the equipment in the first place. The difference is in the organizational relationships between the individuals involved in the production. With integration, the employees in publisher B and printer $\mathrm{A}$ are working together within one organizational unit: the firm. With the other two options, the employees remain in separate firms. ${ }^{19}$

Manage. Decis. Econ. 36: 384-400 (2015)

DOI: $10.1002 / \mathrm{mde}$ 


\subsection{Implications of Opportunism Literature and Information Flow Analysis}

The implications of these alternative solutions for the organization of human capital are similar to those of the opportunism literature, but there are differences. Because investments that are not specific to a particular firm have a clear market value, there is no need to transfer information about the production process or about the potential market returns on the investment: the investor has other alternatives should the original buyer renege. Thus, when specificity is absent, complex transfers are likely to be unnecessary, and market transactions are sufficient. However, for specific investments, the decision makers at the supplier asked to make the investment (printer $\mathrm{A}$ in the preceding example) will have to be convinced that it will be able to realize a return. These decision makers could be convinced by being educated on both the process and the market potential, or they could be 'convinced' by being purchased. ${ }^{20}$ The greater the cost of transferring the information, the more likely the second alternative-vertical integration-will be the optimal contracting choice. Thus, predictions from complex information flow analysis are likely to be similar to those derived from asset specificity arguments. However, there is a difference between the two theories: information flow analysis is motivated by the efficiency of economizing on information transfers (integration lowers the cost of repeated complex information transfers), whereas specificity is motivated by incentives. This difference leads to different predictions whenever: (i) the information transferred is simple, but the investments required are specific; or (ii) the information transferred is complex, but the investments required are not specific.

An example of simple information transfers but specific investments can be found in the pharmaceutical industry. Small start-up firms often develop ideas and take them to the preclinical stage, or somewhere further down the path of phase I, II, or III of the trials before selling the rights to a larger company. The larger company completes the clinical trials and, if successful, takes care of production, distribution, and marketing of the product. To do so, the larger company must make investments in FDA trials, the marketing, and the distribution of the product, which are specific to the product. The opportunism literature predicts that the firms would integrate because of the specific nature of the investments. ${ }^{21}$ However, this is often not the contract of choice. Instead, and consistent with information flow analysis, employees from the smaller firm often transfer information about the product, probability of success, and the potential value of success to the employees of the larger firm (including the decision makers). Information about the product or production process is often very simple information. The chemical composition or the specific protocol for producing must be documented for the FDA, and often, these documents are sufficient to convey the information a third party would need to produce it. Information about the probability of clinical success is often specific to the particular genes or molecules being studied. The smaller firm may have a scientist who has more information about that; however, to the extent that it is based on accepted science, the buyer is likely to have its own scientists who are able to develop their own conclusions at a relatively low cost. Further, the smaller firm's scientists can transfer that information by investing in the upfront trials and proving - using third party standards (the FDA) - that the product is likely to succeed. The further along the FDA approval process path, the more likely it is to succeed. The smaller firm's employees may also put together some sort of market analysis, making the case that further investment in the drug is warranted. Rather than vertically integrating, these smaller firms often sell the relevant information to the larger firms through contracts that transfer (at least some of the) rights to the information to the larger company. Some options, such as licensing contracts, distribute the profits from success and require an ongoing working relationship between the small startup employees and the larger distributor's employees in a way that bears certain similarities to integration and is more in line with Williamson's (1991) hybrid form of governance. Other options involve one-time payments and are less like integration. In contrast to the asset specificity argument, the complex-information-flows approach predicts that the degree to which the contract resembles integration will be a function of the complexity of information: as the number of complex information transfers increases, the benefits of integration increase. In this case, the information transfers are simple, and information flow analysis predicts that across-firm transactions are more likely. Because in all cases, appropriable specific investments are required, the asset specificity argument predicts that integration (or some contracting arrangement that closely resembles integration) would be the more likely solution in all cases.

This difference in predictions between the asset specificity argument and information flow analysis also holds for specific investments in human capital. 
Monteverde and Teece (1982) 'hypothesize that assemblers will vertically integrate when the production process, broadly defined, generates specialized, nonpatentable know-how. When production processes are of this kind, both assembler and supplier are exposed to the possibility of opportunistic recontracting' (p. 206). Because human capital cannot be owned, the human capital specificity argument is related to organizational issues just as information flow analysis is: specific human capital is more likely to be employed within the firm. However, the same differences between information flow analysis and human capital specificity described earlier hold here. ${ }^{22}$ Specifically, information flow analysis suggests that specificity is not enough; the information to be transferred must also be sufficiently complex. For example, a consulting firm may engage in a significant amount of research that is specific to a particular client, research that generates 'nonpatentable know-how'. The individuals within the consulting firm have thus made investments in human capital that are specific to the client. However, conveying the results of the research may involve only simple information flows such as a report or presentation and the research may be of a limited duration, thereby reducing the benefits of integration. Azoulay's (2004) analysis of CROs is a good example of this. The investments in human capital made by anyone testing a particular drug are specific to that drug. When the pharmaceutical company is interested in learning from the results, the information flows are complex, and Azoulay finds that the research is more likely to be conducted by the pharmaceutical company's own employees. However, if the pharmaceutical company is only interested in data on the efficacy and safety of the drug, the information is simple and, he finds, more likely to be transferred across the market from an independent CRO's employees to the pharmaceutical company's employees. In contrast, the opportunism literature emphasizes the appropriability of the specific investment, regardless of the complexity of the information being transferred and reasons that specific human capital will be employed within the firm.

The emphasis on production efficiency as opposed to incentives has further implications for information flow analysis that are not found in the asset specificity arguments. First, information flow analysis suggests something about which party will buy and which will sell in an acquisition. Specifically, the party that controls the more complex information is more likely to end up owning the merged entity. This is due to the cost of transferring the information. Economizing on information flows suggests that whichever party has

Copyright () 2014 John Wiley \& Sons, Ltd. the least complex information will transfer it to the party with the most complex information, thereby saving the cost of transferring the most complex information. Incentive alignment suggests that because the party that began with the most complex information is now in possession and control of all of the relevant information, it would also be beneficial to have that party own residual rights to the information. The opportunism literature is silent on this point. ${ }^{23}$

Second, risk preferences play a role in information flow analysis. Williamson (1985) deliberately avoids relying on risk aversion in part because it 'deflects attention from core efficiency purposes' (p. 390). This is true here as well, but because information flow analysis centers on transfers between individuals, the role of risk aversion is difficult to avoid. To see how it impacts the analysis, return to the printer and publisher. Even if publisher B sells the information to printer A and that transfer takes place at a sufficiently low cost so that both have the same assessment of the likely outcomes and their payoffs, printer A's leadership may not choose to make the investment simply because it is risk averse. Instead, printer A's leadership may choose to allow printer A to be purchased by publisher B even though the cost of that approach exceeds the cost of transferring the information. That is, the cost of the (simple) information transfer is less than the cost of integrating, but the cost of the risk (risk premium) plus the cost of the information transfer may exceed the cost of integrating. ${ }^{24}$

\section{INFORMATION FLOWS AND PHYSICAL ASSETS}

Ownership of physical assets is related to information flow analysis directly and indirectly. The direct effect is related to information flows that are tied to a physical asset. When frequent, complex information transfers require the use of a particular piece of physical capital, that physical capital becomes part of the calculus that goes into determining firm boundaries in terms of human capital. Returning to the printing equipment example, if the equipment requires accumulation of complex information by those who work with the equipment, individuals would gradually develop a stock of information related to the equipment that would make it beneficial to include all of those individuals within the firm boundary with the capital equipment. Thus, even if there are no information transfers between the employees, it would be beneficial to include all of those individuals within the same 
firm because of their interactions with the equipment. The equipment links the employees together.

The indirect effect is due to emphasis on incentives in determining ownership of physical capital. The last section described the asset specificity argument where the incentive to expropriate quasi-rents associated with specific investments gives rise to integration. In the property rights literature (Grossman and Hart, 1986; Hart, 1988), incentives associated with ex post returns drive decisions about asset ownership ex ante. Moral hazard literature emphasizes the incentive costs for the principal. But firms do not have incentives, people do. Actions taken by firms are actions of the individuals working within the firm, individuals who are unlikely to have the same incentives of other individuals working within that firm (other employees) or, perhaps more importantly, other stakeholders in the firm (for example, shareholders). Thus, analysis of the boundaries of physical capital requires an understanding of the organization and incentives of the individuals who decide how the physical capital is deployed.

Not all of the literature on physical capital examines the underlying incentives of the individuals. For a number of important articles, because they focus on ownership of physical assets, the incentives of individuals within the firm are assumed to be consistent with the firm's ownership; however, it is not clear that assumption is valid. For example, Forbes and Lederman (2010) explore the ownership patterns of regional airlines, some of which are owned by major carriers. Their argument centers on unscheduled interruptions in service that cannot be anticipated (e.g., weather cancellations). They argue that integration may allow a major (carrier) to more efficiently respond to the schedule disruption by improving its access to resources that had been allocated to the regional' (p. 770). But the owned regional is not making the decision; an employee at the owned regional is. Thus, the relevant question is whether the employee at an owned regional has more of an incentive to efficiently respond to a schedule disruption than an employee within an independent regional. The answer to that depends on the specific contract written in each case. Later in the article, they address the possibility that the independent regional could have a contract that gave its employees incentives to account for costs of delays and cancellations on the major; however, they continue to talk about the independent regional rather than the employee of the independent regional. The problem with this is that it masks the problem the major-owned regional faces: how to generate the right incentives for its employees to make the decisions that

Copyright () 2014 John Wiley \& Sons, Ltd. account for the major carrier's costs and benefits. Because employees are making the decisions, some sort of mechanism must be developed that gives the employee the appropriate incentives. That is true whether it is an employee of the major-owned regional or an employee of an independent regional. ${ }^{25}$ Thus, it is unclear that simply owning a regional carrier is the most cost-effective method of addressing the challenges a major faces in the event of unforeseeable circumstances such as weather cancellations.

In another example, Baker and Hubbard (2003) examine the ownership patterns of trucks. Some trucks are owned by shippers (companies that produce products that need to be shipped to different locations) and some are owned by carriers (companies that own fleets of trucks and sell their services to shippers). One of the challenges in owning a truck is keeping it full on all legs of a trip. A shipper may need a product shipped from points $A$ to $\mathrm{B}$, but the owner of the truck would like to generate revenue from a backhaul (shipments from points B to A) as well. Because carriers own many trucks, Baker and Hubbard argue that they will have a stronger incentive to find a backhaul than a shipper even though a shipper can contract with a broker who may interact with many other shippers, independent truck owners, and carriers. Part of their argument rests on the assertion that brokers (intermediaries between shippers and carriers) 'have weaker incentives (than carriers) to find particularly good matches, because they do not own trucks and are thus less able to appropriate as large a share of the value they create' (p. 556). However, this is only true if the individual employee of the carrier who is coordinating truck schedules is also the owner. If the individual who is actually doing the coordinating is an employee of a carrier company, which is likely in most cases, the question is whether the incentives of the employee at the carrier are stronger than the incentives of an employee at the broker. Again, when we get down to the individual employees, the incentives are less clear.

Both of the preceding studies present evidence that is consistent with their incentive-based arguments. However, the observed relationships are also consistent with other hypotheses including those that are derived from information flow analysis. Incentive arguments are correlated with information flow analysis because moral hazard problems are greater when the ability to observe behavior is weaker. When the inability to observe behavior is due to complex information flows, the two frameworks yield empirically equivalent outcomes. This can be seen by considering 
how information flows affect both the airline and trucking industry organizational relationships.

In the airline industry, although information about the weather itself is simple information, the information transfers required as a result of weather cancelations require many real-time interactions between numerous employees, which are often complex. Which employees to shift to which activities will depend on the specific circumstances related to the flight, the day, the weather, and so on. Similarly, which assets to use, which flights to delay, and which employees have the relevant information-all of this will be specific to the particular circumstance. One of the key arguments of this paper is that organizing economic activity within a firm economizes on transfers of complex information. Specifically, in this example, when the individuals from the major carrier and the regional carrier that interact in the event of a weather event at an airport are the same individuals that have interacted in numerous other weather events, information flow analysis suggests that complex information will be transferred more efficiently than if they interacted less frequently. Integration can increase the likelihood that the same individuals at the regional carrier and the major carrier are involved because of the following: (i) integration represents a credible commitment to the individuals at the regional carrier by the owners of the major carrier and/or (ii) integration gives the owners of the major carrier more control over which individuals at the regional carrier are managing the weather event. Under these circumstances, integration will be a more efficient solution owing to a more efficient transfer of complex information. That is, as Forbes and Lederman argue, an increase in unforeseeable circumstances such as weather changes will be handled more economically through vertical integration. However, the benefit of integrating using information flow analysis does not rely on an incentive argument; instead, it is related to the increased productivity due to complex information flows (holding incentives constant).

Good fits for backhauls in the trucking industry requires that dispatchers know about the trucks as well as the truck drivers. In one of the interviews I conducted, a carrier employee said that drivers have individual characteristics such as where they like to drive and how they interact with customers (both shippers and receivers). These are unique to each driver. Some shippers or receivers also have very specific expectations. Dispatchers can use this knowledge to try to ensure a good match between driver and shipper or driver and receiver. However, developing the

Copyright () 2014 John Wiley \& Sons, Ltd. knowledge in the first place requires repeated interactions. Thus, integration of driver with dispatcher may be beneficial in arranging backhauls because of information complexity. ${ }^{26}$

\section{INFORMATION FLOWS AND OTHER ECONOMIC THEORIES ON FIRM BOUNDARIES}

Information flow analysis can also be used to augment other efficiency arguments related to firm boundaries such as scale economies and vertically related monopolies.

\subsection{Scale Economies}

In 1997, the US Antitrust Merger Guidelines were revised to explicitly account for efficiencies such as scale economies. Some authors have pointed out that scale economies can be realized unilaterally, thereby raising questions about their use as a defense in a merger investigation (e.g., Farrell and Shapiro, 2001). A more general question is whether scale economies can be realized between firms. In some cases, they can be. In such cases, whether or not efficiencies from scale economies require conducting the activity within a firm's boundaries can depend on the complexity of the information transfers-scale economies are not the determining factor. Two examples illustrate this point.

Consider large investments in plant and equipment. The owner of a manufacturing plant may benefit from employing many people because the use of the equipment and coordination of the activity require relatively frequent and complex information exchanges. An office building, however, might be filled with no one who works for the owner of the building. The office building's equipment does not require complex information to be transferred, and there is little need to coordinate. Thus, although scale economies in physical assets may involve significant capital investments, efficiency does not necessarily require that the investing firm's employees utilize the assets. Scale economies can be realized even when the users of the asset are not integrated with the owners of the asset. Scale economies can be realized more efficiently within a firm's boundaries when they are combined with frequent and complex information flows.

Financial scale economies derive from economizing on borrowing. The argument is that it is cheaper for a large corporation to borrow money from a financial institution (or the market) and then allocate funds 
internally on the basis of its own criteria. It is true that there are fixed costs associated with ensuring that a loan is worth making. These costs will reduce the per-dollar charge of a large loan relative to the charge of a number of small loans that sum to the value of the large loan. However, the cost of dealing with many small loans must be incurred either by a bank or by a larger, parent firm making a loan to an internal client (subsidiary). It will be more efficient for the bank to make the loan to the parent company and have the parent company distribute the investment to its smaller subsidiaries only when the parent firm is more efficient at determining the credit worthiness of a particular investment at one of its subsidiaries than a bank would be. When will that happen? When there are complex information flows between the smaller entities and the larger, parent firm, enabling the parent firm to assess the smaller entities' credit worthiness at a cost that is lower than the cost to the bank of developing a similar assessment.

\subsection{Hierarchies}

In a series of studies, Garicano et al. (Garicano, 2000; Garicano and Rossi-Hansberg, 2006; Garicano and Santos, 2004; Garicano and Hubbard, 2003, 2005) also focus on human capital, arguing that organizations are beneficial as hierarchies that allow those with specialized human capital to spend more of their time on the problems or opportunities in which they specialize. Garicano (2000) identifies different levels of employees: production workers and multiple levels of problem solvers. Production workers handle the most frequent (or easiest) problems. Problems they cannot solve are referred to the first level of problem solvers who handle the next most frequent (or next level of difficulty) problems. Each subsequent level of problem solver handles increasingly less frequent (or more difficult) problems with increasing degrees of specialization. The result is a pyramidal hierarchy with the smallest group at the top being most specialized, handling the least frequent (or most difficult) problems.

In an extension of Garicano (2000), Garicano and Santos (2004) contend that a major role of the firm 'is to match opportunities with talent' (p. 499), which happens when less skilled labor refers the more difficult problems to the next level up in the hierarchy. They show that when the more capable individual is the one who knows of an opportunity, there is a spot contract that will encourage referring the opportunity to the less capable when it is efficient to do so.
However, when the less capable is the one who becomes aware of the opportunity, there is not a spot contract that will result in efficient referral; the less capable individual has an incentive to hold on to the opportunity even though he knows he is less qualified than the more capable individual. Partnerships can solve this incentive problem by committing both agents to income sharing ex ante and thus diminishing the incentives of the less capable to hold onto an opportunity instead of referring it. Garicano and Hubbard (2003) extend the partnership idea to firm boundaries, where firm boundaries are defined as 'the scope of revenue-sharing arrangements across individuals' (p. 496).

Like information flow analysis, the hierarchy argument also relies on costly information transfers and is, thus, consistent with information flow analysis in some respects. The benefit of transacting within a firm's boundaries, according to the hierarchy argument, is incentive alignment. The hierarchy argument holds because it is costly to transfer information about effort by the agent receiving the problem: 'Since the effort that an agent puts into dealing with a particular opportunity is unobservable, the agent who is referred an opportunity and obtains only a share of the output has an incentive to free ride by providing too little effort' (Garicano and Santos, 2004, p. 500). This may overstate the case-output can be a good proxy for effort in some cases; however, the point is well taken. Monitoring effort is more difficult in many cases. For instance, Alchian and Demsetz (1972) base their argument on the difficulty in monitoring effort when production requires teamwork. Monitoring individual effort in a team setting may be more difficult (costly) because the information is more complex. Monitoring requires reviewing information based on an understanding of the task and the process instead of simple outputs. To the extent that is true, the hierarchy argument is also based on complex information: the more complex the information required to effectively monitor effort, the greater the incentive-alignment benefit to sharing revenues, that is, organizing within a firm.

Unlike information flow analysis, the unit of analysis in hierarchy analysis is the agent; in information flow analysis, the unit of analysis is the information. Consequently, information flow analysis includes benefits to organizing within a firm that are not contemplated in hierarchy analysis. ${ }^{27}$ In hierarchy analysis, heterogeneous agents transfer problems through a hierarchy until they reach an agent who can address the problem. Problems are separable, with each part addressed by a different individual. Team effort only 
comes into play to the extent that there is a benefit to transferring opportunities from one level to another. Problems are not solved through joint effort of multiple individuals. Problems are not interdependent. Information flow analysis, by contrast, emphasizes the varying complexity of the information transferring between agents, much of which may be transferred as part of addressing challenges and opportunities that are not separable and benefit from input of multiple agents. Thus, information flow analysis complements hierarchy analysis: hierarchy analysis focuses on heterogeneity of agents and the benefits of transferring information about opportunities (and challenges) from one agent to another while information flow analysis provides a more detailed description of the type of information that is transferred, allowing analysis on a transfer-by-transfer basis.

There are a few empirical studies on hierarchies that are also relevant for information flow analysis. First, Garicano and Hubbard (2005) investigate the relationship between law firm partners and law firm associates. They hypothesize that managers with greater cognitive capacity will benefit more from associates with greater cognitive capacity because it allows the partner to 'better leverage his talent' (p. 356). Their findings support their hypothesis: partners in law firms are more likely to hire associates who come from the same-tier school. That is, if the partner is from a top-tier school, it is more likely that the associate is from a top-tier school as well. Similarly, partners within a law firm are more likely to be from the same tier as other partners within the same firm. However, these findings can also be explained by information flow analysis. Hiring associates from similar institutions may lower a firm's communication costs, as associates with similar training and thought processes will be able to transfer their ideas more efficiently. Put differently, hiring agents from the same or similar institutions may allow a firm to capitalize on an investment already made by the educational institutions in lowering the cost of transferring complex information between their graduates.

Second, there is evidence that the number of direct reports to CEOs has increased in recent years (e.g., Rajan and Wulf, 2006; Guadalupe and Wulf, 2010). Specifically, the breadth (as measured by the number of direct reports to the CEO) increases, and the depth (as measured by the number of levels between the CEO and the highest authority in an individual profit center within the company) of the company decreases. A decrease in depth arguably improves the information flows between CEO and division managers by

Copyright () 2014 John Wiley \& Sons, Ltd. eliminating a level of management. Some have argued that it also increases the ability of the firm to act quickly to market changes. However, that increase would come at a cost. Assuming a CEO was operating at capacity (in terms of time) prior to an increase in breadth, an increase in breadth must be accompanied by a decrease in the cost of interacting with each report. One way this could happen is to decrease the complexity of information transfers between each report and the CEO. This could happen as a company's products become more commoditized. Production in such cases may become a more rote process and require less complex information transfers between the leadership and the units themselves, allowing the leadership to take on a more direct role. Consistent with this, some evidence suggests that as competition increases, breadth increases. ${ }^{28}$

\subsection{Successive Monopoly Markup}

The standard story of vertically related monopolists is that the sum of the profits they earn is lower than what they could earn if the monopolists were vertically integrated (double-monopoly markup problem). The standard response to this is to vertically integrate and thereby increase both total surplus and the total profits. $^{29}$ This solution, however, ignores moral hazard costs generated by creating a larger firm. If a vertically related supplier is integrated into its customer, the management of that vertically related supplier will not have the same motivation to be efficient because there is another layer between management and the residual claimant. These moral hazard costs could be addressed by an incentive contract at what has now become a subsidiary, but if the incentive contract is based on the subsidiary's performance, this could lead to the same double-monopoly markup problem that motivated the merger in the first place. The difference is that now the double-monopoly markup takes place between internally related monopolists, but it is no less costly.

The trade-off between the moral hazard costs and the double-monopoly markup cost is, at least in part, a trade-off between information costs. Moral hazard costs are reduced as the information the principal has about agent behavior increases. Similarly, Jeuland and Shugan (1988) show that under certain circumstances, information about the vertically related firm's behavior can lead to across-firm contracting solutions that reduce the double-monopoly markup problem. The net benefits of merging in this case will partly be a function of the cost of transferring information 
regarding the double-monopoly markup problem relative to the cost of transferring information about agent behavior.

\section{CONCLUSION}

Coase (1937) emphasized the benefits of examining the foundations on which theories rest in his exploration of the firm. In this paper, I argue that a foundation of the firm is information and that analysis of information flows is warranted because of the central role they play in determining optimal organizational form. In particular, the benefits of organizing human capital within a firm increase with the complexity of information to be transferred and the number of times those transfers take place. An examination of other theories shows that they ultimately rely on an understanding of information flows, and when those are considered, the conclusions are more refined and, in some cases, different.

Although the firm is the central character in this paper, information flow analysis can be extended to examine other forms of organizations and informationsharing mechanisms. Teams, another focus of economic literature, are one example. Other mechanisms developed by the market may provide more fertile ground for organizational research. Toyota's lean production system and GE's metrics and meeting structure are just two examples. Breaking these and other examples down into their component parts-the information that is transferred-might provide guidance to managers as they wrestle with the question of how best to organize their economic activities.

\section{NOTES}

1. As is the case with many assets including steel molds for plastic parts and prints for printed circuit boards.

2. Some form of information flow analysis can be found in many different disciplines within economics. The economic geography literature notes the role of physical proximity in transferring complex information (Sturgeon et al., 2008). Economic historians identified something akin to this years ago (e.g., Buttrick, 1952, Chandler, 1977). Personnel economics (Lazear and Gibbs, 2009) also considers information flows between individuals in organizational design.

3. Although the discussion will center on firm boundaries, I follow Demsetz (1988) in that I am less interested in whether or not an activity actually takes place within a firm's boundaries and treat firm-like activities (e.g., long-term repeated across-firm relationships) the same as within-firm activities. This paper is thus about the desirability of certain types of organizational relationships. Once determined, as Masten (1988) points out, the legal structure of the firm is an efficient method of creating one set of relationships in one step. However, it is not the only option and whether or not a legal firm is chosen to impose those relationships is a separate question.

4. Williamson (1985), p. 21.

5. For example, Lafontaine and Slade's (2007) description of the transaction cost literature relates incentives to specificity in the following way: 'specific investments generate quasi rents, and each of the parties to a contract has incentives to endeavor to capture those rents' (p. 649).

6. Bloom's taxonomy remains '(o)ne of the most widely used ways of organizing levels of expertise' (University of North Carolina's Center for Teaching and Learning, Bloom's Taxonomy of Educational Objectives, as found on their website in 2013: http://teaching.uncc.edu/articles-books/best-practice-articles/goals-objectives/

blooms-taxonomy-educational-objectives). Although a number of theorists have attempted to revise the taxonomy, the initial framework remains the standard in education.

7. Different authors use the word 'knowledge' in different ways. In particular, Bloom's use of the word knowledge should not be confused with that of Azoulay (2004) whose description of knowledge would be much higher in Bloom's taxonomy.

8. Note the difference with Tadelis (2002), who concentrates on contract complexity instead of information complexity.

9. Blair and Lafontaine (2005) cite an example of the difference between employment and contracting in the context of franchising: 'in a private conversation with one of the authors of this book, a franchisor mentioned how, if he had hired one of his franchisees, he could never have brought himself to pay him a salary commensurate with the level of profit that this franchisee was earning' (p. 217). This begs the question: why enter into a franchisee relationship? One answer is that incentives are stronger when the franchisee is an independent business owner where compensation of zero is a real possibility. Implicit in this argument is a greater sense of commitment to employment and positive compensation with an employment contract instead of a franchise contract. Further, to the extent that an employer is able to contract with an independent contractor in a way that replicates the commitment from and to the employee, the employer has created what Demsetz (1988) calls a 'firm-like' relationship, and the cost-benefit analysis described here applies. That is, the distinction here is between contracting forms that are more firm-like and less firm-like, not necessarily between those that are within a firm's legal boundaries and those that are firm-like but just outside a firm's boundary.

10. In a related discussion about teams, Lazear and Gibbs (2009) argue that team interactions will be necessary when the task requires multiple skills and or a greater capacity than that of a single individual. However, this by itself is not enough to explain the existence of teams. 
Many products and services require multiple skills, but not all of those are combined in a team setting. The team becomes beneficial if those skills need to be integrated in a way that is accomplished most efficiently via frequent transfers of complex information.

11. See Demsetz (1988).

12. However, within the consulting firm, complex information is transferred frequently and over long periods. This improves the consulting firm's efficiency with any given client. On each assignment, the employees of the consulting firm learn more about that specific topic that is of value because they work on similar projects over and over again with different clients. The value of this learning is, however, low to any given client who typically faces that particular problem less frequently.

13. Bernheim and Whinston (1986) define common agency as a situation in which actions by one agent affect multiple principals.

14. See, for example, Milgrom and Roberts (1992).

15. Some firms in the pharmaceutical industry actually do hire customers when the drug treatment and/or the information to be gained from the consumer is sufficiently valuable. Some hemophilia patients, for instance, are hired as employees of the pharmaceutical company in part because the pharmaceutical company is trying to gain a deep understanding of (or complex information about) the needs of these patients.

16. There are other reasons that vertical integration between a manufacturer and a retailer would not be beneficial. For instance, if the manufactured good is most efficiently sold in combination with goods from many other manufacturers (e.g., grocery stores), integration is not likely to be a beneficial solution.

17. I do not consider all other theories that rely on incentives (e.g., relational contracts as found in Baker et al., 2002); however, because information flow analysis rests on the economies of scale associated with transferring complex information, it is going to be distinct from all of these as well. My point here is to explore the implications of those differences in a few of these literatures.

18. See Lafontaine and Slade (2007) for a review of the empirical literature supporting the theory.

19. As discussed earlier, this is consistent with Coase (2006) who does not appear to consider the purchase of equipment to be vertical integration but instead focuses on the organization of human capital.

20. The value of integration here is that it is an upfront payment to the supplier. The supplier is not subject to the same level of risk of poor market analysis or potential duplicity.

21. Williamson (1991) discusses a hybrid form of governance, which, while moving in the direction of integration in terms of control and incentives, does not move to the polar case of hierarchy. However, his discussion is not based on complexity of information and thus differs from the distinction described here.

22. Klein (1988) may have had complex information flows in mind in his analysis of the organization of human capital. He illustrates the benefit of integration in the context of the Fisher-GM merger: 'By integrating with Fisher, General Motors acquired the Fisher Body organizational capital. This organization is embedded in the human capital of the employees at Fisher but is in some sense greater than the sum of its parts. The employees come and go but the organization maintains the memory of past trials and the knowledge of how to best do something (that is, how to make automobile bodies)' (p. 208). The source of the gain to integrationthe organization embedded in the human capital of the employees - is not entirely clear. However, one possibility is consistent with information flow analysis: scale economies associated with complex information flows.

23. See, for example, Williamson's (2000) discussion. Other theories, such as Hart (1988) and Grossman and Hart's (1986) analysis of asset ownership, do provide guidance on which party should be the buyer, that is, which party should end up as the owner of the residual rights of control.

24. There is a similar effect when capital constraints are binding. Specifically, even if information flow analysis suggests party A would acquire party B, if party A has limited capital, party B may end up purchasing party A. Another way of looking at it is that party A will need to raise the capital necessary to buy party $\mathrm{B}$. This requires party $\mathrm{A}$ to transfer complex information about the benefit of integration to an investor. Party B may be the most efficient source of that capital.

25. At one point, the authors touch on the incentives of the employees, arguing that employees at major-owned regionals have an incentive to make sure the parent firm is profitable because if the regional is sold, the employee might be subject to lower wages as an employee at an independent regional. However, the link is not obvious (the regional might be sold because it was profitable), and the evidence presented suggesting lower wages for independent regionals applies to pilots-not to the employees making the relevant decisions. Further, earlier in the article, Forbes and Lederman state that the major-owned regionals are kept separate from the major so they can benefit from the lower-cost structure that applies to nonunionized workforces. That is, so they can benefit from the cost structure that the independent regionals enjoy. If there is no wage differential, the employees' incentive to make sure the parent firm is profitable no longer exists.

26. They still need the incentive to act on it, but organizing within the firm lowers the cost of transferring information and will therefore improve efficiency, holding incentives constant.

27. Garicano et al. do consider different types of information and the costs of transferring them, but the two types that they consider and the variation in the cost of information transfers within those categories do not necessarily correspond with complexity as defined in this paper. Garicano (2000) and Garicano and Rossi-Hansberg (2006) look at information flows from two perspectives: the cost (to a given individual) of accumulating knowledge and the cost of communicating (between individuals). The lower the cost of communicating, the more likely there will be specialization of knowledge because people can be asked to solve problems at a lower cost. The lower the cost of accumulating knowledge, the more likely individuals are to gather the information instead of asking others to solve problems. Information flow 
analysis makes no distinction between communication and knowledge accumulation-both are information transfers.

28. Note that the results in Guadalupe and Wulf (2010) are based on a sudden exogenous event: elimination of trade barriers, including tariffs, between the USA and Canada. Specifically, they find that those industries most affected by the tariff reduction (with the greatest tariffs prior to the agreement) had the largest increase in breadth and largest decrease in depth. One possible explanation is that liberalization forced CEOs to become more competitive by focusing on the liberalized products and terminating diversification efforts. Consistent with this explanation, they do find that there was less diversification after liberalization.

29. See for example, Carlton and Perloff (2005).

\section{Acknowledgements}

I thank Ken Heyer, Francine Lafontaine, Ben Klein, Scott Masten, Jagadeesh Sivadasan, and two anonymous referees for many useful discussions and comments on this paper.

\section{REFERENCES}

Alchian AA, Demsetz H. 1972. Production, information costs, and economic organization. American Economic Review 62(5): 777-95.

Azoulay P. 2004. Capturing knowledge within and across firm boundaries: evidence from clinical development. American Economic Review 94(5): 1591-612.

Baker GP, Hubbard TN. 2003. Make versus buy in trucking: asset ownership, job design, and information. American Economic Review 93(3): 551-72.

Baker GP, Gibbons R, Murphy KJ. 2002. Relational contracts and the theory of the firm. Quarterly Journal of Economics 117(1): 39-83.

Bernheim BD, Whinston MD. 1986. Common agency. Econometrica 54(4): 923-42.

Blair R, Lafontaine F. 2005. The Economics of Franchising. Cambridge University Press: New York, NY.

Bloom B (ed.) 1956. Taxonomy of Educational Objectives, Handbook 1 Cognitive Domain. Longman: New York.

Bolton P, Dewatripont M. 1994. The firm as a communication network. Quarterly Journal of Economics 109(4): 809-39.

Buttrick J. 1952. The inside contract system of the Winchester Repeating Arms Company of New Haven, Connecticut. Journal of Economic History 12(3): 205-21.

Carlton DW, Perloff J. 2005. Modern Industrial Organization (4th edn), Pearson: Upper Saddle River, NJ.

Casadesus-Masanell R; Spulber D. 2000. The fable of Fisher Body. Journal of Law and Economics 43(1): 67-104.

Chandler A. 1977. The Visible Hand, Harvard University Press: Cambridge, Mass.

Coase RH. 1937. The nature of the firm. Economica 4: 386-405.

Coase RH. 1988. The nature of the firm: Origin. Journal of Law, Economics, and Organization 4(1): 3-17.

Coase RH. 2006. The conduct of economics: the example of Fisher Body and General Motors. Journal of Economics and Management Strategy 15(2): 255-278.
Demsetz H. 1988. The theory of the firm revisited. Journal of Law, Economics, and Organization 4(1): 141-161.

Farrell J, Shapiro C. 2001. Scale economies and synergies in horizontal merger analysis. Antitrust Law Journal 68(3): 685-710.

Forbes S, Lederman M. 2010. Does vertical integration affect firm performance? Evidence from the airline industry. The Rand Journal of Economics 41(4): 765-790.

Gant J, Ichniowski C, Shaw K. 2002. Social capital and organizational change in high-involvement and traditional work organizations. Journal of Economics and Management Strategy 11(2): 289-328.

Garicano L. 2000. Hierarchies and the organization of knowledge in production. Journal of Political Economy 108(5): 874-904.

Garicano L, Hubbard TN. 2003. Firms' boundaries and the division of labor: empirical Strategies. Journal of the European Economic Association 1(2-3): 495-502.

Garicano L, Hubbard TN. 2005. Hierarchical sorting and learning costs: theory and evidence from the law. Journal of Economic Behavior and Organization 58(2): 349-369.

Garicano L, Rossi-Hansberg E. 2006. Organization and inequality in a knowledge economy. Quarterly Journal of Economics 121(4): 1383-1435.

Garicano L, Santos T. 2004. Referrals. American Economic Review 94(3): 499-525

Grossman S, Hart O. 1986. The costs and benefits of ownership: a theory of vertical and lateral integration. Journal of Political Economy 94(4): 691-719.

Guadalupe M, Wulf J. 2010. The flattening firm and product market competition: the effect of trade liberalization on corporate hierarchies. American Economic Journal: Applied Economics 2(4): 105-127.

Hart O. 1988. Incomplete contracts and the theory of the firm. Journal of Law, Economics, and Organization 4(1): 119-139.

Hayek F. 1945. The use of knowledge in society. American Economic Review 35(4): 519-30.

Jensen M, Meckling W. 1976. Theory of the firm: managerial behavior, agency costs and ownership structure. Journal of Financial Economics 3(4): 305-360.

Jensen M, Meckling W. 1992. Specific and general knowledge and organizational structure. in Contract Economics, Werin L, Wijkander H (eds). Blackwell: Oxford; 251-274.

Jeuland A, Shugan S. 1988. Channel of distribution profits when channel members form conjectures. Marketing Science 7(2): 202-210.

Klein B. 1988. Vertical integration as organizational ownership: the Fisher Body-General Motors relationship revisited. Journal of Law, Economics, and Organization 4(1): 199-213.

Klein B. 2007. The economic lessons of Fisher BodyGeneral Motors. International Journal of the Economics of Business 14(1): 1-36.

Klein B, Crawford RG, Alchian AA. 1978. Vertical integration, appropriable rents, and the competitive contracting process. Journal of Law and Economics 21(2): 297-326.

Kogut B, Zander U. 2003. Knowledge of the firm and the evolutionary theory of the multinational corporation. Journal of International Business Studies 34(6): 516-29. 
Lafontaine F, Slade M. 2007. Vertical integration and firm boundaries: the evidence. Journal of Economic Literature 45(3): 629-85.

Lazear EP, Gibbs M. 2009. Personnel Economics in Practice (2nd edn), John Wiley \& Sons, Inc: Hoboken, NJ.

Masten S. 1988. A legal basis for the firm. Journal of Law, Economics, and Organization 4(1): 181-198.

Milgrom P, Roberts J. Economics, Organization and Management, Prentice Hall: Englewood Cliffs, New Jersey; 1992.

Monteverde K. 1995. Technical dialog as an incentive for vertical integration in the semiconductor industry. Management Science 41(10): 1624-38.

Monteverde K, Teece D. 1982. Supplier switching costs and vertical integration in the automobile industry. The Bell Journal of Economics 13(1): 206-213.

Pindyck R, Rubinfeld D. 2013. Microeconomics (8th edn), Pearson: Upper Saddle River, NJ.

Rajan RG Wulf J. 2006. The flattening firm: evidence from panel data on the changing nature of corporate hierarchies. Review of Economics and Statistics 88(4): 759-773.
Sturgeon T, Van Biesebroeck J, Gereffi G. 2008. Value chains, networks and clusters: reframing the global automotive industry. Journal of Economic Geography 8(3): 297-321.

Tadelis S. 2002. Complexity, flexibility, and the make-orbuy decision. American Economic Review: Papers and Proceedings 92(2): 433-437.

United States Department of Justice and the Federal Trade Commission. Horizontal merger guidelines, April 8, 1997 revision.

Williamson OE. 1979. Transaction cost economics: the governance of contractual relations. Journal of Law and Economics 22(2): 233-261.

Williamson OE. 1985. The Economic Institutions of Capitalism, The Free Press: New York.

Williamson OE. 1991. Comparative economic organization: the analysis of discrete structural alternatives. Administrative Science Quarterly 36(2): 269-296.

Williamson OE. 2000. The new institutional economics: taking stock, looking ahead. Journal of Economic Literature 38(3): 595-613. 